\title{
AKED包A \\ DILEMAS SOBRE O TRABALHO EM TEMPOS DE PANDEMIA DE COVID-19
}

English title: DILEMMS ABOUT WORKING IN COVID-19 PANDEMIC TIMES

doi》10.33726/akdpapers2447-7656v11a72021p17-35

PESSOA, Marcelo ${ }^{1}$ - (iD https://orcid.org/0000-0002-9193-4604

RESUMO: O presente trabalho se debruça sobre questões contemporâneas relacionadas às novas dinâmicas de relação do homem com o trabalho e destes com as empresas. O objetivo deste levantamento, foi o de reunir num único texto, o maior volume possível de informações sobre o estado da arte da legislação, sobre os ajustes corporativos e as adaptações humanas empreendidas nas relações de trabalho durante a Pandemia de COVID-19. Metodologicamente, realizamos uma pesquisa bibliográfica exploratória, combinada com uma varredura digital em repositórios jornalísticos da internet que tratassem deste tema. Como resultados, esta pesquisa apresenta o fato de que, apesar da sedução pelo home office e pelo teletrabalho terem sido objetos de desejo das pessoas antes da pandemia, tanto as corporações quanto os seus colaboradores pretendem, senão uma retomada do trabalho presencial, ao menos um formato híbrido nos limiares da pós-pandemia.

PALAVRAS-CHAVE: Pandemia, COVID-19, Teletrabalho, Home Office

\begin{abstract}
The present work deals with contemporary issues related to the new dynamics of the relationship between man and work and between them and companies. The purpose of this survey was to gather in a single text, the largest possible amount of information on the state of the art of legislation, on corporate adjustments and human adaptations undertaken in labor relations during the COVID-19 Pandemic. Methodologically, we carried out an exploratory bibliographic search, combined with a digital scan in internet journalistic repositories that dealt with this topic. As a result, this research presents the fact that, despite the seduction by the home office and teleworking, have been objects of people's desire before the pandemic, both corporations and their collaborators intend, if not a resumption of face-to-face work, at least one hybrid format in the post-pandemic thresholds.
\end{abstract}

KEYWORDS: Pandemic, COVID-19, Telework, Home Office

\footnotetext{
${ }^{1}$ Doutor em Letras pela Universidade Estadual de Londrina. Orientador e Docente na UEMG - Unidade Frutal. Departamento de Linguística, Letras, Comunicação e Artes - DLLCA.
} 


\section{AKED恶}

\section{INTRODUÇÃO}

No final do ano de 2019, ninguém, no mundo inteiro, talvez pudesse imaginar o cenário de ficção que viria a se desenrolar pelo Planeta, a partir dos primeiros dias do ano de 2020. Isto é, se a nós pudesse ter sido exibido um vídeo trailer sobre o futuro, ou como se tem dito nos embates populares e pelas redes sociais virtuais, onde se tratam dos mais diversos temas do convívio humano, se nos fosse dado um spoiler sobre o como seria o ano de 2020, certamente o prenúncio de uma pandemia, sobretudo, com os graves desdobramentos sobre a existência humana, econômicos, sociais, políticos, históricos, psicológicos, que se performaram em torno da COVID-19, não comporia quaisquer vídeo clipes produzidos por quem quer que fosse.

$\mathrm{E}$, por ter mencionado o spoiler, vejo que é pertinente aqui uma breve digressão, momento em que peço licença ao leitor para fazê-lo. Falando-se em spoiler, portanto, vale dizer que, ao lado da já disseminada acepção semântica sobre a palavra em voga (spoiler), sabe-se que seu significado tem se tornado fato corriqueiro nas mesmas redes sociais às quais recorremos para coletar nossos dados.

Nestes ambientes virtuais, o emprego deste vocábulo tem nos remetido à ideia de que spoiler é uma "revelação antecipada". Ao lado disso, isto é, de um uso de certo modo assim já consagrado, é fato, também, que nos estudos etimológicos, a figura do verbete spoiler se refere bem mais adequadamente ao significado de espoliador, ou seja, daquilo que avilta, depleta ou ultraja e, neste segundo sentido, talvez um eventual spoiler sobre o COVID-19, dado ao conhecimento público que se tinha sobre o vírus ainda no final de 2019, explicasse e antevisse com melhor exatidão 0 atual momento pandêmico por nós experimentado a partir do começo de 2020.

Foi nesse contexto que, em meados dos meses de janeiro, fevereiro em alguns recônditos do Planeta, ou a partir de março de 2020 noutros lugares (conforme a evolução do ciclo de contágio do Novo Corona Vírus), que as restrições de contato social impostas pelas razões assépticas da pandemia forçou a que muitas empresas precisassem alocar boa parte de seus 


\section{AKED』A}

colaboradores para condições de trabalho remoto, nos formatos denominados como teletrabalho e ou em home office (termos a serem esclarecidos adiante).

Segundo a "Organização Internacional do Trabalho" (OIT), o "teletrabalho" é "a forma de trabalho realizada em lugar distante do escritório e/ou centro de produção, que permita a separação física e que implique o uso de uma nova tecnologia facilitadora da comunicação" (Conceito disponível em: JUSBRASIL, 2020). Enquanto isso, o termo "home office", traduzido do inglês, significa literalmente "escritório em casa".

$\mathrm{Na}$ prática, tais definições nada mais implicam em que o profissional passe a ter repentinamente à sua disposição uma estrutura corporativa fincada na própria residência para realizar suas tarefas de trabalho como se estivesse alocado na empresa.

Em contexto de pandemia, a demanda por mais "espaços alternativos para a continuidade da prestação de serviços" se elevou, isto é, a procura por tais adaptações sofreu robusto incremento e, assim, a estas duas expressões (ao teletrabalho e ao home office) passaram a se associar variações como o telecottage (o "telecottage" é geralmente um tipo de estabelecimento comunitário formulado para auxiliar os membros da comunidade com o aprendizado, o acesso à tecnologia, o acesso ao trabalho etc.), o coworking (espaços destinados ao compartilhamento de uso, geralmente voltados ao labor tradicional). Além disso, no término do período mais restritivo do isolamento social, estas dinâmicas de exercício do "trabalho remoto" incorporaram-se no uso de cafeterias, de hotéis, de áreas de lazer públicas, de praças de alimentação em shoppings etc. Em suma, qualquer lugar que ofereça a tecnologia e espaço necessário para o desempenho das funções pôde servir como terreno para o labor corporativo (CATHO, 2020).

Agora, sobre a diferença fundamental entre um e outro modo de trabalho executado a distância (especialmente falando do teletrabalho e do home office - vistos em nosso estudo como epicentros da preocupação das corporações), convém resgatarmos a seguinte formulação: 


\begin{abstract}
AKED更A
Importante notar que o teletrabalho não precisa ser realizado necessariamente em domicílio (o que o distingue da modalidade clássica de "trabalho em domicílio" ou home office), podendo ocorrer em telecentros, centros satélites, telecottages, ou mesmo sem um espaço definido (teletrabalho nômade ou móvel) (CALVETE \& HORN, p. 307).
\end{abstract}

E, não diferentemente do cenário geral engendrado pela história natural da pandemia, vimos que a produtividade acadêmica relativa ao atendimento burocrático e didático à distância e à produção intelectual docente e discente também se viu migrando para estas mesmas estruturas de interação em regimes alternados e ou simultâneos de teletrabalho e de home office (cf. CALVETE \& HORN, p. 307).

Em razão desta reconfiguração dos formatos de troca social e de desempenho no trabalho, é que, neste paper, o objetivo mais razoável a ser traçado foi o de perscrutar em que medida as atividades de trabalho remoto têm impactado o ser humano ou que possamos minimamente insinuar como ainda poderão afetar a sociedade no contexto da Pandemia de COVID-19.

Justifica a realização de um texto como este, no começo do ano de 2021, a ainda insuficiência de atos voltados à revisão sistemática imediata dos postulados legais e culturais sobre os aspectos legais e sobre a função social do trabalho, bem como dos tratados econômicos, antropológicos e sociológicos sobre a conduta humana e as adjacentes respostas governamentais que, a toque de caixa, estão sendo dadas ante ao problema da recuperação econômica, social e emocional num almejado e iminente momento póspandemia que já se aproxima de todos nós (sobretudo com a chegada das vacinas), no Brasil e na América do Sul, desde o final de 2020 e início de 2021.

Desse modo, espera-se que os resultados desta investigação e o compêndio de dados ora apresentados alimente a realização de debates e de novos trabalhos. E, que de algum modo, este pequeno esforço de renovação e de atualização de nosso corpus seja academicamente útil aos pesquisadores das Ciências Sociais e das Ciências Humanas que vierem a se debruçar na tentativa de compreender e descrever os novos fatos que nos rodearam neste inacreditável ano de 2020. 


\section{AKED}

\section{METODOLOGIA}

Metodologicamente, de um lado, pela falta de acervo próprio ao tema e, por outro lado, devido às restrições de deslocamento e, consequentemente, do pouco acesso a acervos bibliográficos físicos consolidados pela tradição científica e atualizados sobre o assunto, optamos por realizar uma varredura digital em vários sites na internet, com vistas às discussões jornalísticas que permeiam esta matéria, imprimindo-se ao presente texto, portanto, um grau elevado na temperatura das notícias selecionadas quanto ao clamor e expressões da sociedade sobre nossa temática.

Importante frisar que, ao lado do respeito que devotamos aos conteúdos de nossa tradição acadêmica, é oportuno lembrar que a produção intelectual sempre tende, por índole, a dar protagonismo àquilo que está em pauta na seara universitária, ao jargão corrente nos bastidores de maior prestígio científico, e, não necessariamente, dar enfoque apenas aos anseios e demandas efetivas ou mais imediatas de nossa sociedade.

Assim, para tentar equilibrar nosso texto entre um e outro polo, apesar das restrições de trânsito e de acesso já expostas, traremos, sempre que possível, fundamentos técnicos minimamente razoáveis igualmente extraídos de repositórios digitais de informação, desde que confiáveis e ou rastreáveis para tudo o que aqui se irá afirmar.

Vale dizer a este respeito que obviamente não ignoramos a existência de produção científica recente, oriunda, particularmente, das Ciências Sociais e das Ciências Humanas que nos pudessem amparar, visto que toda ela também jaz disposta em outros tantos compêndios digitais destinados para tal fim, tais como acervos bibliográficos de universidades, bancos de teses e dissertações. Ressaltamos que, prescindir desse tipo de acúmulo de conteúdos é uma opção intencional.

Pauta nossa decisão ao menos dois argumentos: a) o desejo de aqui se construir um texto que tenha uma feição de "banco de dados", de coletâneas de manchetes de jornal; e, b) a constatação de que a nossa "ciência" como um todo, tem claudicado na direção de dar respostas concretas e assertivas para a 


\section{AKEDIA}

sociedade no tocante ao Novo Corona Vírus. Condição esta que, se não nos permite desconfiar de nosso arcabouço científico, nos autoriza, no mínimo, a colocar em xeque tais postulados, abrindo-se, com isso, uma fenda, por meio da qual se vislumbra a possibilidade de realização de propostas de recomposição do corpus teórico e para a coleta de dados mais próximos da atualidade e da emergência sociocultural com a qual lidamos.

Outro dado metodológico importante a ser ressaltado, é o de que, em tempos de produção de conteúdos intensamente veiculados por meios e repositórios digitais, é comum que a checagem das informações científicas ou mesmo de dados preliminares de pesquisa (como é o nosso caso aqui) sejam mais facilitadas. Neste sentido, lembramos que, o que, em princípio, pode parecer uma vantagem técnica (a facilidade de checagem via meios digitais), por outro lado, dá margem para o surgimento de fenômenos como o do fakechecking (falsas checagens de origem das informações).

Desse modo, ao lado de nossa preocupação em informar nosso leitor / pesquisador, nos impusemos a possibilidade de ampla checagem da origem dos dados que nos orientaram na construção deste paper. Noutros termos, isto quer dizer que, se de um lado não nos é possível empreender checagens irretocáveis de tudo aquilo que tem sido publicado na internet, por outro lado, ao oferecermos um rol de sites e de links em que a mesma informação tem aparecido, não eliminamos a possibilidade de imprecisão dos dados coletados, porém, compartilhamos com nossos leitores a rastreabilidade das informações, o que, se não confere maior validade aos nossos estudos, ameniza-se o impacto no tocante à credibilidade e origem dos fatos narrados.

Convém esclarecer também, que sabemos que não é por culpa da "ciência" propriamente dita que tais devolutivas não têm ocorrido a contento e a tempo da inesperada e elevada demanda social por respostas. Logo, sabe-se que a produção científica, do mesmo modo que outras atividades da lide humana tem, ao seu próprio tempo, um ritmo singular de se construir.

Como neste artigo tratamos de temática que realiza correlações atinentes ao contexto socioeconômico, para melhor entender o que se passa com a nossa "ciência", lembramos que há, no mercado financeiro, uma máxima 
que diz que a análise estratégica de balanços empresariais ou do mercado de ações sobre a obtenção de lucros no passado não oferece certeza de lucros no presente ou no futuro.

Transpondo esse conceito para os domínios de nossa tão atacada, combalida e carente de recursos "ciência", vemos que as respostas por meio dela até então dadas à sociedade global, se postas à luz da analogia feita acima sobre os fatos da economia de mercado, estabelecem um grau de confiabilidade que se fundam muito mais num cenário de prognósticos da sorte astrológica, de apostas de cassino ou no imaginário catastrófico de youtubers do que na predição técnica, consistente e confiável feitas a partir de modelos tecnológicos ou do rigor metodológico cientificamente sustentáveis.

Ou seja, os parâmetros científicos disponíveis via conceitos, teorias e história referente a outras pandemias e ao comportamento da própria sociedade de pouco ou quase nada nos serviram para ajudar aos cientistas sérios a realizarem predições entregáveis quanto ao futuro humano ante ao Sars-CoV-2.

Somente para mencionar parte dos desencontros recentes entre "ciência" e realidade social imediata, destacamos o dilema fomentado especialmente pela OMS (Organização Mundial da Saúde) e o Ministério da Saúde brasileiro e seus correlatos pelo mundo afora. Divergiram ou "escorregaram" em questões sobre o uso ou não de máscaras, sobre a aplicação ou não de lockdown, sobre o tempo de incubação do novo vírus, sobre o contágio e a possibilidade de recontaminação, sobre a imunidade de rebanho ser ao mesmo tempo possível e ou inalcançável, sobre o tempo de recuperação do infectado, sobre a eficácia ou não de usos off label (segundo a ANS - Agência Nacional de Saúde Suplementar, o medicamento chamado "offlabel" é aquele cuja indicação do profissional assistente diverge do que consta na bula) de medicamentos como o "Remdesevir", a "Hidroxicloroquina", o "Avipiravir", o "Kevzara", a "Ivermectina", o "Anitta", sobre a definição precisa do perfil do grupo mais vulnerável ao novo corona vírus, sobre o tempo de ascensão / platô / queda da curva de infecção, sobre as estimativas de letalidade, sobre a segurança / eficácia / tempo de produção de vacinas, sobre a possibilidade e ou segurança de pessoas já infectadas tomarem a vacina. 


\section{AKED』A}

RESULTADOS E DISCUSSÕES

Em nossa varredura digital sobre o modo de implementação do trabalho remoto, em sites como do "INFOMONEY" (o "site" de finanças mais confiável do Brasil) e do "INVESTING" ("site" que trata dos mercados financeiros globais, com informações e dados apresentados em 44 idiomas), notamos que se deu ampla divulgação a dados de uma pesquisa realizada na INTEL (A "Intel Corporation" é uma empresa multinacional e de tecnologia sediada em Santa Clara, Califórnia, no Vale do Silício, EUA), com pelo menos 150 líderes de TI (profissionais ligados aos setores de tecnologia de informação).

Embora tais sites não sejam, stricto sensu, acadêmicos e, portanto, não preocupados ou com o dever de análise e validação dos dados divulgados, é interessante que se perceba na leitura fria dos números que divulga, o viés das alterações de produção e de consumo quanto à variação dos mercados globais em tempos de pandemia.

Em nossa apuração do que se veiculou por ali, vimos que na referenciada pesquisa mostrou-se que, para $79 \%$ dos trabalhadores em TI (Tecnologia da Informação), o afazer remoto é item que traria desafios significativos à gestão da produção e difusão da informação nas empresas. Entre os entrevistados, $77 \%$ disseram que o teletrabalho iria aumentar os riscos em segmentos de cibersegurança (proteção de computadores e demais dispositivos de dispersão de conteúdos). Entretanto, é imprescindível pontuarmos, segundo fontes da mesma pesquisa, que a Pandemia de COVID19 simplesmente acelerou os processos de implantação de teletrabalho, os quais já estavam em franca expansão na INTEL:

In many businesses, most devices are no longer located where IT staff operate. Fleets today comprise on-premise devices, remote devices, and even devices that don't have a user, such as smart vending machines, ATMs, or hub devices in conference rooms. [Em tradução livre: "Em muitas empresas, a maioria dos dispositivos não está mais localizada onde a equipe de TI opera. As frotas hoje incluem dispositivos locais, dispositivos remotos e até mesmo dispositivos que não têm um usuário, como 


\section{AKED』A}

máquinas de venda automática inteligentes, caixas eletrônicos ou dispositivos de hub em salas de conferência"] (INTEL, 2019).

Em relação aos inúmeros obstáculos postos diante dos humanos nestes novos e simultaneamente velhos tempos, muitos entraves ainda restam a serem vencidos no caminho da consolidação do home office. Neste sentido, deparamo-nos com informações que temos acompanhado em fóruns de internet, em jornalismo via streaming ou mesmo em noticiários televisivos ou radiofônicos, que dão conta de que este percalço sobre a reconfiguração dos espaços e das relações de trabalho se concentra focado em itens como o da disponibilidade de mobiliário adequado ao exercício funcional caseiro e na falta de ambientes adequados para a entrega produtiva do trabalho feito a partir de casa.

Outro fator social que tem chamado bastante a atenção nos relatos e fatos jornalísticos associáveis ao tema "teletrabalho", é aquele que se volta à detração dos afetos (familiares e não familiares) em função do isolamento social, e também de conflitos que acontecem face ao convívio full-time com as pessoas dentro destes mesmos círculos afetivos:

Sobre isso, o psicanalista Flávio Carvalho Ferraz, professor do "Instituto Sedes Sapientiae", [...] problemas de relacionamento e neuroses que já existem tendem a se manifestar na atual situação de quarentena. Os tipos de conflito que podem surgir também se relacionam com a classe social das pessoas. Para algumas, assumir as funções domésticas da empregada dispensada em tempos de pandemia é uma fonte de estresse e origem de brigas (SANT'ANNA, 2020).

Nos mesmos apontamentos jornalísticos a que temos recorrido com frequência, vê-se que, quanto ao quesito de acesso a bens eletrônicos e à eficiência das condições tecnológicas pré-existentes na vida das pessoas antes do Novo Corona Vírus (propriedade ou posse de equipamentos, bem como o domínio de seus sistemas operacionais) há um gap tecnológico e financeiro a ser superado. 


\section{AKEDIA \\ $E$, justamente num momento em que as interações pessoais e}

profissionais passaram a acontecer predominantemente em regimes virtuais, a defasagem tecnológica ganha prevalência como problema socioeconômico, especialmente se vista sob os termos em destaque nos parágrafos anteriores. Destacam-se, neste critério, contudo, fatores cuja solução perpassa a questão econômica, como a da necessidade do aumento da velocidade de tráfego de dados de internet e a aquisição de melhores computadores ou de aparelhos celulares e demais itens para a satisfação plena da intensa rotina de trabalho a distância, tais como mobiliário, iluminação e revestimento acústico de ambientes.

Tal circunstância limitante ainda se defronta com o fato da obrigação de enquadramento da sociedade aos Decretos de isolamento social, lavrados pelas autoridades sanitárias, políticas e jurídicas que regem nosso convívio social:

Não obstante, e mesmo considerando a temporalidade da

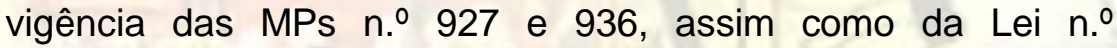
13.982/2020 (com exceção do artigo $1^{\circ}$ ), algumas de suas normas parecem apontar para um caminho de retorno duvidoso, notadamente as que envolvem a aplicação de inovações tecnológicas no universo laboral. [...] A MP n.ำ 927/2020 já tinha adotado o teletrabalho como uma das medidas para enfrentar o corona vírus (artigo $3^{\circ}, \mathrm{I}$ ), assim como criado ou flexibilizado regras do mesmo, como se constata no seu artigo 4‥ Merece ser destacado que a adoção daquela forma de labor foi estendida também para estagiários e aprendizes (artigo 5) (BARBOSA JUNIOR, 2020).

Por sua vez, é senso comum nas discussões pela internet, que as diferentes ferramentas de comunicação virtual, como o "Zoom" e o "Microsoft Teams", e de gestão do trabalho e da conduta diária, como o "Trello" e o "Slack", e. g., passaram a exigir do usuário um volume de habilidades no manuseio (além do já mencionado dispêndio de recursos financeiros) que dificulta a expansão e reconfiguração dos contratos de trabalho sob os moldes da nova realidade pandêmica. 


\section{AKEDIA}

Acerca da interpretação do referido art. 75-D, CLT, há, essencialmente, duas correntes de entendimento. De um lado, há quem defenda que a Lei supra deixou em aberto a possibilidade de fixação da responsabilidade pelo custo e manutenção dos instrumentos necessários à realização do teletrabalho, podendo o contrato escrito atribuí-lo ao trabalhador.

Torna-se possível, assim, ao empregado ter que arcar com algumas despesas relativas à prestação de serviço remoto, exigindo-se, apenas, que isso conste de contrato escrito. De outro lado, há corrente, com a qual compartilhamos, no sentido de que, em se tratando o insumo de típica ferramenta para o exercício do trabalho, o custo é do empregador, incidindo, no particular, o princípio da alteridade, de acordo com o qual os riscos e custos do negócio correm por conta do empregador (art. 2ㄴ, CLT). Ou seja, corre sob a exclusiva responsabilidade do empregador os riscos do empreendimento, da atividade e do contrato de trabalho celebrado com seus empregados (GASPAR \& VEIGA, 2020).

Outro fator relevante, segundo um membro do "Conselho de CEOs do Wall Street Journal", é o de que: "Quando você trabalha em casa, às vezes parece que está dormindo no trabalho". Na prática, isto nos remete às armadilhas emocionais criadas pelo fato de os indivíduos estarem longe do escritório por muito tempo.

Reuniões online em regime de teletrabalho ou de home office podem redundar em funcionários bem mais cansados do que normalmente ficavam e, devido à nova condição dos novos espaços de trabalho ou mesmo do ambiente residencial adaptado como extensão do espaço corporativo, dificulta-se a transição do "lugar emocional trabalho" para o "lugar emocional vida privada" (BLOOMBERG, 06/10/2020).

Desse modo, há quem afirme que esta nova relação do homem com seu trabalho habitual, é premissa sociocultural capaz de interferir nos coeficientes de felicidade ou de infelicidade. $O$ aumento da felicidade de trabalhar em casa pode, por sua vez, tornar os trabalhadores mais produtivos. Porém, nas atuais circunstâncias, no entanto, é difícil ter certeza se o trabalho em casa ou no escritório é mais eficiente, já que é difícil comparar as diferentes realidades que 
funcionários possuem dentro de suas próprias casas (CIDADEVERDE.COM, 2020).

Devido a narrativas como esta, é que a Microsoft criou um novo produto, que pretende dar soluções ao problema. O "Together Mode", que se constitui numa ferramenta tecnológica que coloca os participantes de videochamadas em um espaço virtual, como se estivessem num auditório, numa sala de reuniões ou numa cafeteria. Este recurso tem o propósito de tentar recriar minimamente um "lugar emocional de se estar num escritório", amenizando-se, assim, o desconforto recém-descoberto no desenlace das funções de trabalho remoto.

Sintomas como insônia, depressão, fadiga têm sido pautas recorrentes em consultórios da medicina alopática, da psiquiatria e de atendimentos psicológicos:

[...] a principal causa de tanto mal-estar é a quebra da rotina. A mudança no ritmo de vida interfere no nosso relógio interno. Nossas células estão programadas para produzir hormônios em certos horários. Com a quebra, o metabolismo se desajusta. No início da pandemia, o principal motivo das consultas era insônia, depois passou a ser ansiedade e agora é depressão. Junte-se [a isso] a longa exposição às telas. A luz azul emitida pelos dispositivos eletrônicos influencia a fabricação de melatonina, o hormônio que avisa ao corpo que a noite chegou. Com a overdose de telas, o cérebro entende que é dia o tempo todo e não deixa o [indivíduo] desligar. Até a síntese de cortisona, o hormônio do estresse, cuja produção cai à noite, é afetada. Diante das telas, seus níveis permanecem altos, levando à insônia. E assim, as pessoas começaram a varar madrugadas e seu relógio [biológico] foi ficando cada vez mais bagunçado. A privação de sono derruba a resistência, compromete a regeneração dos tecidos, acelera o envelhecimento, provoca fadiga, irritabilidade, queda da concentração. [...] um estudo, [realizado] com 3890 pessoas, publicado no The Lancet Psychiatry, em 2017, demonstrou que a dificuldade para dormir não é sintoma, mas causa de ansiedade e depressão (NABUCO, 2020).

Nesta parte da discussão de nossos resultados de pesquisa, salientamos que, como o espaço de trabalho e boa parte das relações dos funcionários entre si, e destes com o empregador e de todos com o serviço 


\section{AKED四}

foram alteradas significativamente e, ao que tudo indica, muitas das tendências atuais serão implementadas em caráter definitivo, é salutar que sob o ponto de vista da revisão dos contratos sociais a serem feitas, que novas legislações trabalhistas sejam pensadas para delimitar a abrangência dos direitos e dos deveres dos agentes envolvidos que agora, ao usarem a residência como espaço de trabalho, não só fizeram migrar parte dos custos operacionais da empresa deixando-as às expensas do empregado, como também assistem seus colabores avançarem no perigoso território dos sofrimentos psíquicos e emocionais.

A reboque dessa premissa, vale recordar que, assim como a ascensão da economia movida por freelancers gerou perguntas e processos judiciais, sobre o que significava ser um empregado formal com vínculo tradicional ou um trabalhador autônomo, no início dos anos 2000, a popularidade do trabalho remoto nestes anos de 2020 pressionará a sociedade por criação e mudanças em Leis que rotineiramente são construídas em torno da suposição de que as pessoas trabalhariam sempre no espaço convencional típico de um ambiente corporativo.

Emblemático disso é um antigo estudo brasileiro sobre os deslocamentos domicílio-trabalho, em que já se houvera revelado que o transbordo era uma das atividades mais desagradáveis que as pessoas faziam regularmente em suas rotinas de trabalho (PEREIRA \& SCHWANEN, 2013). Cabe destacar que esta investigação é considerada "antiga" (apesar de feita nos idos da década de 2010), tendo-se em vista que praticamente todo o referencial incorporado em nossa atual escrita é composto de notícias, formulações conceituais e opiniões manifestas imediatamente neste ano de 2020, em plena ocorrência da Pandemia de COVID-19 e, portanto, trata-se de fatos, que, no jargão jornalístico, são "quentes”, ou simplesmente "recentes".

$\mathrm{Na}$ mesma direção daquele desalento sobre os transbordos (vistos em PEREIRA \& SCHWANEN, 2013), num levantamento feito pelo "Escritório de Estatísticas Nacionais da Grã-Bretanha" (dados repercutidos pelo jornalismo via internet, em "sites" como do INFOMONEY, do CIDADEVERDE.COM, ou do TERRAVIVA.COM, 2020), as impressões, de certo modo, se mantiveram (NADER, 2020). 


\section{AKED霆}

Noutra investigação correlata, feita pela "Universidade de Montreal", no Canadá (2020), identifica, contudo, haver uma relação direta entre o trajeto até o trabalho e o desenvolvimento de problemas como a Síndrome de burnout (transtorno psíquico de caráter depressivo, precedido de esgotamento físico e mental intenso) (NADER, 2020).

Nestas pesquisas (rastreáveis a partir do "site" SPEDNEWS.COM.BR, mas, também, presentes em outros muitos veículos digitais já indicados), descobriu-se, em síntese, o que já fora detectado por Pereira \& Schwanen (2013), isto é, o problema de que os passageiros diários do metrô, por exemplo, têm menor satisfação com a vida, níveis mais baixos de felicidade, maior ansiedade, especialmente se comparados com aqueles sujeitos que não precisavam utilizar-se desta prática em seus deslocamentos diários.

A variável recente neste quesito, no entanto, é a de que, até então, nenhuma sociedade contemporânea havia experienciado, em larga escala, a migração do exercício do trabalho presencial nos escritórios corporativos para os espaços caseiros ou alternativos, como o coworking ou o telecottage.

Se, num primeiro momento, a interrupção das idas frequentes aos espaços dos escritórios e das corporações até soou "charmoso", sob o ponto de vista da produtividade e da maior permanência das pessoas junto aos seus bens materiais e de seus entes queridos (pessoas e pets), neste final de quarentena (final, ao menos no estágio atual desta primeira onda de contágio do vírus), a sedução inicial face ao teletrabalho, ao home office e seus correlatos já esteja se convertendo em repulsas e descontentamentos.

Há, ainda, em nosso levantamento, a emergência de estudos em que se apontam o aumento da felicidade pelo fato de se trabalhar em casa. Uma empresa de recursos humanos, a "Adecco", fez uma pesquisa que foi bem difundida por sites como do INFOMONEY, da ACEAMP (Associação Comercial e Empresarial de Ampére), e do CANALEXECUTIVO (Blog focado no mundo corporativo), em junho de 2020 - há pelo menos três meses após o início da pandemia no Brasil - mostrando que os profissionais entrevistados, em sua maioria, se sentiam mais produtivos trabalhando a distância. 
A Adecco, líder mundial em recrutamento e seleção, realizou, então, uma pesquisa com 1.179 profissionais para entender como foi a adaptação deles e das companhias que trabalham no formato home office, durante 0 período de distanciamento social, e quais as expectativas para o que começava a ser chamado de "o novo normal".

Segundo seu levantamento, $48 \%$ das empresas dos participantes aderiram ao home office, e destes, $86 \%$ tiveram facilidade na adaptação ao trabalho home office, enquanto que $67 \%$ se sentiram mais produtivos trabalhando a distância. Já, $60 \%$ concordam que a tecnologia se tornou mais presente no trabalho (CANALEXECUTIVO, 2020).

Portanto, como nosso principal objetivo neste artigo é o de compilar informações, dados e perguntas que possam subsidiar estudos sobre a Pandemia de COVID-19 e seus efeitos, vemos que inúmeras questões ainda serão revistas pela legislação pertinente. Como, por exemplo, a de quem deve pagar pelo custo do trabalho doméstico? Como serão realizadas as demissões? De que forma serão contabilizadas as horas trabalhadas? Como monitorar o tempo de trabalho contratual em um mundo onde ninguém fisicamente observa ninguém? E, até que ponto, as empresas podem vigiar os trabalhadores em casa? E até em que medida os suportes tecnológicos serão autorizados a na invasão da privacidade em nome do controle de tudo isso?

Igualmente, salientamos que os postulados sobre a digestão emocional face aos fatos da pandemia também precisará ser observada a partir de novas óticas.

\section{CONCLUSÃO}

Com a iminente retomada dos trabalhos presenciais seja tida como certa ainda no primeiro semestre de 2021, mesmo que a vacinação em massa no Brasil esteja na fase do "engatinhando", em boa parte do mundo e com as inúmeras questões levantadas nesse período de home office e teletrabalho forçados, ainda é um tanto incerto saber como será o escritório do futuro ou se haverão tantos escritórios como os que existiam até o início da pandemia. 
Fato, é que o novo cenário impôs desafios às organizações, tanto para gestão das equipes quanto em questões ligadas à oferta de aparatos de tecnologia e alocação de infraestrutura. Como a adoção do trabalho remoto deu-se de modo repentino, as pessoas e nem todas as companhias estavam preparadas para que seus funcionários trabalhassem num regime de jornada integral à distância.

Nesse sentido, muitas corporações relataram uma queda na produtividade logo no começo da pandemia, o que, de certo modo, tem contribuído para que estudos como os que apresentamos aqui, evidenciem que o interesse na manutenção de equipes inteira em home office, ou a adoção permanente do teletrabalho, talvez precise de alguns ajustes ou nem mesmo aconteça em larga escala.

Há pesquisas que caminham meio que na contramão de uma propalada "tendência" de adesão cega e feliz à atividade remota. Essa alternativa foi tida inicialmente como a única possibilidade de continuidade da atividade econômica face aos decretos de lockdown que passaram a vigorar mundo afora e em alguns cantos do Brasil. A nós, restará esperar que o tempo ratifique ou retifique esta ou aquela posição.

Evocamos, neste término de compilação de dados, os resultados da "PNAD COVID-19" (Pesquisa Nacional por Amostra de Domicílios - PNAD COVID-19). Pesquisa considerada pioneira no Brasil, no sentido de constituir a primeira divulgação de estatísticas experimentais elaboradas pelo IBGE (Instituto Brasileiro de Geografia e Estatísticas) sobre temas socioeconômicos específicos relacionados à COVID-19. Trazemos tal estudo à baila, visto que seus dados estão alinhados com a estratégia de modernização do Instituto e permitem a ampliação das ofertas de informação ofertadas aos usuários dos sistemas de informação do governo, bem como, contribuem para que o leitor do presente texto possa retroalimentar os dados aqui coletados.

Em suma, na pesquisa "PNAD COVID-19" supra (IBGE, 2020), demonstra-se que, no Brasil, aconteceu um recuo do teletrabalho: em setembro de 2020, o "PNAD COVID-19" demonstra que 8,073 milhões de pessoas 


\section{AKED』A}

trabalhavam de forma remota, e que esse número já é menor que o mês de agosto, com 303 mil pessoas a menos nesta condição (IBGE, 2020).

A realocação de espaços, tornada mercadologicamente e socialmente apta pela Pandemia de COVID-19, foi alvo de estudo divulgado pelo INFOMONEY, numa pesquisa oriunda da empresa de consultoria imobiliária "Cushman \& Wakefield" - prestadora de serviços que atua no segmento de aluguel de espaços em edifícios de alto padrão. Nela, revelou-se que $84 \%$ das empresas que ocupam escritórios de alto padrão já retornaram gradualmente ou pretendem retornar até o fim deste ano de 2020 aos seus espaços físicos. Além disso, 59\% delas não têm intenção de reduzir ou não conseguem afirmar ainda se reduzirão o tamanho de seus escritórios futuramente (SUTTO, 2020).

Com isso, supõe-se como forte a tendência de que as empresas sigam investindo mais em tecnologia e infraestrutura no pós-pandemia. A manutenção, ao menos parcial do trabalho remoto para o pós-pandemia já foi anunciada por algumas grandes empresas, o que manterá a alta demanda por videoconferências, por serviços tecnológicos e pela capacidade de produção dos colaboradores de forma remota (ACEAMP, 2020).

Ou seja, por meio das considerações de Jadson Andrade, que atua como head de inteligência de mercado da "Cushman \& Wakefield" (detentora dos direitos da pesquisa acima indicada), tais resultados foram surpreendentes e mostram que, se o home office ou o teletrabalho não estão literalmente com os seus dias contados em nossa sociedade, é factível crer que ao menos se levará em consideração a possibilidade de convívio de um modelo híbrido de trabalho: "Mesmo diante dos indicadores positivos sobre a adaptação ao formato home office, é possível afirmar que a compreensão por parte das pessoas para um acordo mútuo entre empresas e colaboradores é sempre o melhor caminho" (CANALEXECUTIVO, 2020).

Conclui-se, enfim, segundo a pesquisa aludida da "Cushman \& Wakefield" (SUTTO, 2020), que: "A retomada gradual na ocupação dos escritórios e a intenção de não reduzir o espaço ocupado no pós-pandemia a níveis inferiores aos do pré-pandemia foram dados inesperados". 


\section{AKED』A}

REFERÊNCIAS

ACEAMP. Infraestrutura do home office ainda é desafio para funcionários e empresas!, 26/09/2020. Disponível em: http://www.aceamp.com.br/noticia/infraestrutura-do-homeoffice-ainda-e-desafio-para-funcionarios-e-empresas. Acesso em 25/10/2020, às 18h36min.

BARBOSA JUNIOR, Franscisco de Assim. Sobre a pandemia do coronavírus, tecnologia e o futuro do trabalho. CONJUR, 09/04/2020. Disponível em: https://www.conjur.com.br/2020-abr-09/opiniao-conoravirus-tecnologia-futuro-trabalho.

Acesso em 24/10/2020, às 22h35min.

BLOOMBERG. CEO da Microsoft alerta para desvantagens de trabalho remoto. INFOMONEY, 06/10/2020. Disponível em: https://www.infomoney.com.br/negocios/ceo-da-microsoft-alerta-para-desvantagensde-trabalho-remoto/. Acesso em 25/10/2020, às 14h15min.

CALVETE, Cássio da Silva \& HORN, Carlos Henrique. A Quarta Revolução Industrial e a Reforma Trabalhista: impactos nas relações de trabalho no Brasil. Porto Alegre: CirKula, 2020. Disponível em: https://www.ufrgs.br/fce/wp-content/uploads/2020/09/aquarta-revolucao-industrial-e-a-reforma-trabalhista.pdf.

CANALEXECUTIVO. $67 \%$ das pessoas se sentem mais produtivas em home office. Adecco. Disponível em: https://canalexecutivoblog.wordpress.com/2020/07/29/67-daspessoas-se-sentem-mais-produtivas-em-home-office/. Acesso em 25/10/2020, às 17h28min.

CIDADEVERDE.COM. 6 lições que o mundo aprendeu sobre o home office com a pandemia. Contabilidade, 08/10/2020. Disponível em: https://cidadeverde.com/contabilidade/110961/6-licoes-que-o-mundo-aprendeu-sobreo-home-office-com-a-pandemia. Acesso em 25/10/2020, às 15h37min.

GASPAR, Danilo Gonçalves \& VEIGA, Fabiano Aragão Veiga. $A$ RESPONSABILIDADE PELOS CUSTOS DOS INSTRUMENTOS DE TRABALHO NO REGIME DE TELETRABALHO. ITD - Instituto Trabalho em Debate, 23/07/2020. Disponível em: http://trabalhoemdebate.com.br/artigo/detalhe/a-responsabilidadepelos-custos-dos-instrumentos-de-trabalho-no-regime-de-teletrabalho. Acesso em 24/10/2020, às 22h42min.

IBGE. Instituto Brasileiro de Geografia e Estatística. Pesquisa Nacional por Amostra de Domicílios - $\quad$ PNAD COVID-19. Disponível em: https://www.ibge.gov.br/estatisticas/investigacoes-experimentais/estatisticasexperimentais/2988-np-pesquisa-nacional-por-amostra-de-domicilios-pnadcovid19/27947-divulgacao-mensal-pnadcovid2.html?=\&t=0-que-e, acesso em 26/10/2020, às 20h35min.

INTEL. Remote Management Technology for Business (2019). Disponível em: https://www.intel.com.br/content/www/br/pt/business/enterprise-computers/remotemanagement.html. Acesso em 24/10/2020, às 21h29min.

NABUCO, Cristina. Epidemia de exaustão. Publicação da Sociedade Brasileira de Infectologia. In: Gama Revista, 13/09/2020. Disponível em: 


\begin{abstract}
AKED更A
https://gamarevista.com.br/semana/cansou/exaustao-quais-os-sintomas-e-as-causasdurante-a-pandemia/. Acesso em 25/10/2020, às 14h19min.

NADER, Danielle. 6 LIÇÕES QUE O MUNDO APRENDEU SOBRE O HOME OFFICE COM A PANDEMIA, 2020. Disponível em: http://www.spednews.com.br/6-licoes-queo-mundo-aprendeu-sobre-o-home-office-com-a-pandemia/. Acesso em 09/01/2021.
\end{abstract}

PEREIRA, R. H. \& SCHWANEN, T. Tempo de deslocamento casa-trabalho no Brasil (1992-2009): diferenças entre regiões metropolitanas, níveis de renda e sexo. Brasília: Ipea, 2013.

SANT'ANNA, Emílio. Confinados em casa, casais lutam contra dificuldades da hiperconvivência - Aliar trabalho, casamento e cuidado com filhos são um desafio durante isolamento para reduzir risco de contrair corona vírus. Folha de S. Paulo / UOL: $23 / 03 / 2020$

Disponível

em:

https://www1.folha.uol.com.br/equilibrioesaude/2020/03/confinados-em-casa-casaislutam-contra-dificuldades-da-hiperconvivencia.shtml. Acesso em: 24/10/2020, às $21 \mathrm{~h} 59 \mathrm{~min}$.

SUTTO, Giovanna. 8 em cada 10 empresas que ocupam escritórios de alto padrão devem retomar o trabalho presencial até o fim de 2020. Disponível em: https://www.infomoney.com.br/carreira/8-em-cada-10-empresas-que-ocupamescritorios-de-alto-padrao-devem-retomar-o-trabalho-presencial-ate-o-fim-de-2020/. Acesso em 09/01/2021.

\title{
SITES CONSULTADOS
}

ADECCO: https://www.adecco.com.br/

ANS: http://www.ans.gov.br/

CATHO: https://www.catho.com.br/

INFOMONEY: https://www.infomoney.com.br/

INTEL: https://www.intel.com.br/

INVESTING: https://br.investing.com/

JUSBRASIL: https://www.jusbrasil.com.br/home

SBI: https://infectologia.org.br/

SPEDNEWS: http://www.spednews.com.br/

TERRAVIVA: https://www.terraviva.com.br/ 